\title{
The evolution of perspectives on the role of transfer during multilingual development
}

\author{
Tavakol, Mahboobeh $\triangle$ \\ Islamic Azad University, Science and Research Branch, Yazd (mahboobehtavakol@yahoo.com) \\ Jabbari, Ali Akbar \\ Yazd University, Iran (a_jabbari@hotmail.com)
}

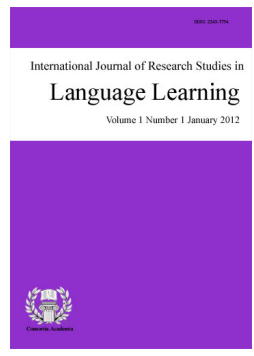

ISSN: $2243-7754$

Online ISSN: 2243-7762

Received: 10 August 2013

Revised: 16 October 2013 DOI: $10.5861 /$ ijrsll.2013.539

Accepted: 17 October 2013

OPEN ACCESS

\section{Abstract}

Multilingualism or using multiple languages by either an individual or a speech community is a unique and commonplace achievement for most of the world's population. The role of L1 on the acquisition of L2 has a long well-documented history. In addition, research from L3 acquisition critically informs current debates concerning the need to investigate the true architecture of multilingualism. The main question is posed as if after a certain level of proficiency is achieved does L1 maintain its privileged role on the acquisition of the subsequent languages or is it possible that language learning is a cumulative process? Several hypotheses are, so far, proposed to account for the role of transfer during multilingual development. The scholars, pondering on what constitute the nature of multilingualism, have approached the acquisition of L3 form the linguistic trend of transfer; however, their proposals are contrasting and seemingly incompatible. This study was an attempt to give a less contaminated picture of the various perspectives towards the interplay amongst the languages during multilingual acquisition, views on the notion of transfer, L3 acquisition hypotheses and synthesis and analysis of studies by erudite researchers in the field. To achieve this, 23 research articles conducted on the effects of bilingualism on L3 acquisition from the perspective of cross-linguistic influence were reviewed meticulously. The end result is a holistic picture of multilingualism. It means to be practical aims at those who are involved in the field of additional language acquisition and has pedagogical implications as far as language learners and practitioners are concerned.

Keywords: L2 acquisition; L3 acquisition; multilingualism; transfer; CLI 


\section{The evolution of perspectives on the role of transfer during multilingual development}

\section{Introduction}

The more multicultural societies become and the more international migration increases, the greater the number of multilingual individuals become. Likewise, in recent times multilingualism transpires as a phenomenon whose nature is to be investigated afresh and on its own research agenda. While second language acquisition is a well-explored, yet a seemingly controversial territory, there is a paucity of introspective data on multiple language learning. Contrastivists, tried to single out areas of L1 and L2 contrast which would present major learning obstacles in the early stage, thus they have been criticized for endorsing an atomistic view of language and perpetuating a naïve view of L2 acquisition (James, 1980). In the meantime, a great number of the current studies on the relatively under-explored field of L3 acquisition owe a considerable debt to another branch of linguistics that associated closely with Chomsky's theory of Universal Grammar (UG afterwards), that is, generative approach. Drawing on the generative framework, language is forcefully positioned as being governed by a set of highly abstract principles that provide parameters which are given particular settings in different languages (Cook, 1985).

Based on the evidence from the relative lack of success of most L2 learners in comparison to L1 learners it is suggested that there may be radical differences of many kinds in the way first and second languages are acquired. But is this also the case in L3 acquisition? The answer to this question depends on the factors that exert a direct effect on the acquisition process and what the learner has at disposal while acquiring an L3.The general consensus is that multilingual acquisition is a nonlinear and complex dynamic process depending on a number of interacting factors. Variability plays a crucial role in the multilingual system as it changes over time (Herdina \& Jessner, 2000; Jessner \& Onysko, 2006). In principle, according to this view of variability there is a qualitative difference between the acquisition of a true L2 and the subsequent acquisition of an L3 and it is necessary to study the acquisition of L3 as something separate from true L2 acquisition in its own research agenda. Several recent studies on L3 syntax have forcefully propagated that L2 is one source of transfer in L3 acquisition (Flynn, Foley, \& Vinnitskaya, 2004; Leung, 2006) and some studies even has indicated that L2 takes on a stronger role than L1 in the initial state of L3 syntax (Bardel \& Falk, 2007; Rothman \& Amaro, 2010).

To the degree that anyone can be introspective about one's own language learning, multilingual individuals anecdotally report that each language learned is equally important and available for playing some role in the subsequent language learning (Cenoz, 2003). Alternatively, it might be the case that neither L1 nor any other language known has an outstanding (Flynn et al., 2004). At present time a heated debate has been developed, in the field of multilingual acquisition, on the effect of previously learnt languages on the learning of a new language has become more nuanced. Not only do researchers continue to ask whether and when transfer will take place, but they additionally ponder on the specific interplay between $\mathrm{L} 1, \mathrm{~L} 2$ and $\mathrm{L} 3 / \mathrm{L}_{\mathrm{N}}$. The generative paradigm has acknowledged that the availability of two or more previously acquired systems at the onset of L3/ $\mathrm{L}_{\mathrm{N}}$ acquisition significantly alters the learning task, path of acquisition and questions can ask. Likewise, a myriad of generative studies on L3 acquisition at the levels of lexicon and syntax, have convincingly advocated a qualitative distinction between the acquisition of a true L2 and the subsequent acquisition of an L3 and one of the most significant contributions to date of generative L3 inquiry involves the articulated models of transfer that have been proposed for the L3 initial state. As already lurking in the argument, there are various and seemingly contradictory views on the true architecture of multilingualism. As such the role of previously acquired languages in the acquisition of a target language is approached from different perspectives. The present state of the art meticulously reviews 23 research studies on the topic of generative L3 acquisition of morpho-syntax, phonology and lexis, as a blossoming area of enquiry, from the vantage point of cross-linguistic influence and critical commentaries by erudite scholars and researchers in the field of multilingualism. The studies are an 
The evolution of perspectives on the role of transfer during multilingual development

infinitesimal but prominent part of studies which began to surface in the latter part of the 2000s.

To give an eye-opening and less contaminated picture of the true architecture of L3 acquisition and how the trend of multilingualism has been challenged by the researchers in the field, we have defined the controversial labels L2 and L3 followed by the presentation of the evolution of perspectives on the notion of transfer. Given that a large number of factors are reported to affect the interaction amongst the languages or say, the likelihood, direction and the extent of transfer in L3 acquisition they are divided into two groups of language and learner based variables and explained in details. The provided list is by no means exhaustive but introduces those variables which are more studied in the mainstream literature. As such, the major proposals with respect to the cross-linguistic influence in L3 acquisition are presented which are all the results of the critical studies by erudite researchers in the field followed by the critical synthesis and analysis of an infinitesimal, yet the most prominent part of the generative L3 acquisition studies. The critical review of the studies conducted on the topic divulged that, at time, the most valid proposal to account for the transfer during multilingual development is the so-called TPM and that further studies are indeed required to better explore the role of CLI in $L 3 / \mathrm{L}_{\mathrm{N}}$ acquisition at different levels of language.

\section{Defining the labels}

\subsection{Second language (L2) acquisition}

Language acquisition as one of the quintessential human traits is the process by which humans acquire the capacity to perceive and comprehend, as well as to produce language. It is mainly concerned with first language (L1) acquisition, which studies infants' acquisition of their native language. This is distinguished from L2 acquisition, which deals with the acquisition (in both children and adults) of additional languages. In general, SLA refers to the process of learning another language after the native language has been learned. As an interdisciplinary field of study, it is mainly concerned with nature of the hypotheses that learners come up with regarding the rules of second language which are either like those of the native language or the language being learned. It is further contended that there might be patterns common to all learners regardless of the native language and regardless of the language being learned (Gass \& Selinker, 2008). In fact, it could be notably argued that a major goal of second language acquisition is the determination of linguistic constraints on the formation of second language rules. One chief difference between L1 and L2 acquisition among others is that the previously acquired first language(s) play(s) a role in the interlanguage development of bilingual learners which is largely undisputed, but what remains controversial is the extent, linguistic domain and potential persistence of the L1 influence during L2 development (Montrul, Dias, \& Santos, 2010, p. 21).

Bilingualism is also a broad term and like L2 acquisition has many forms and configurations. Bhatia (2006) claims that 'bilingualism is a broad and sophisticated field of research, including the study of the nature of the individual bilingual's knowledge and use of two (or more) languages' (p. 5). In principle, the use of the term bilingualism is problematic because the Latin prefix 'bi' means 'two' (Cenoz, 2005). In its strict meaning, it refers to someone whose language is in a steady state and who has learned and now knows two languages. In other words, the end result of second language acquisition is a bilingual speaker. Either the language is being acquired naturally or in the formal setting of classroom through instruction, it is customary to speak generically of second language acquisition (Krashen, 1981).

\subsection{Third language (L3) acquisition}

SLA is usually considered to be a cover term for acquisition of a non-primary language including $\mathrm{L} 3 / \mathrm{L}_{\mathrm{N}}$ as is the case with bilingualism which is often loosely used to incorporate multilingualism. This notwithstanding, L3 acquisition/trilingualism is becoming a prominent and autonomous field of inquiry. As a matter of fact, using multiple languages either by an individual or a speech community has become a unique and commonplace achievement for most of the world's population (Flynn, Foley, \& Vinnitskaya, 2004). A felicitous definition of 
multilingualism has been the subject of debate in the very same way as the definition of second language acquisition. Differing definitions of multilingualism arise on account of two related groups of reasons: those deriving from participants' complex situation with regard to the nature of their use of various languages and those deriving from scholars' differing backgrounds, ideologies and purposes. As a result of the researchers' prolific effort to supply a succinct definition form differing perspectives, there exists a sort of linguistic-continuum in a way that while one may define multilingualism as complete competence and mastery in another language, on the opposite end of the spectrum it is concisely defined as knowing enough phrases to get around using the alternate language.

In recent years, a number of researchers have started to look seriously at the phenomenon of L3/multilingualism as a separate domain of enquiry. In fact, a number of researchers have explicitly or implicitly asserted that L3 acquisition is not another case of adult L2 acquisition. To the extent that multilingual individuals are not so compartmentalized in terms of keeping languages and inter-languages apart, the mixing and merging of various languages known is at the heart of research on multilingualism. The last decade or so has witnessed promising shifts and exciting achievements in the study of language acquisition and language use which have raised the general consensus about the true nature of multilingualism or using multiple languages. The folk wisdom is that multi-linguals, having more than one language at disposal, are more experienced learners and as a result have advantages over bilinguals when acquiring additional languages. Broadly speaking, third language acquisition is mainly concerned with the acquisition of any non-native language acquired beyond the first language either in a naturalistic setting or the environment of one's native language within the context of classroom. Rather than viewing the study of third language acquisition simply as an extension of SLA research, the current trend addresses the L3 learner not as a monolingual acquiring an L2 but instead the term multi-competence is proposed. The term as used by Cook (1995), refers to the linguistic competence of a multilingual learner which is indubitably different from that of a monolingual learner. It is intuitively obvious that a multilingual learner will approach the acquisition process in a different way and the cross linguistic influence will be more complex when three or more languages come into contact (Murphy, 2005). In principle, the label L3 is used to refer to the third language (second non-native) language acquired by the learner in the order of acquisition.

\section{Views on transfer}

Historically, the questions about language transfer raised by Selinker (1996) were obscured for a decade by the important research trend linking first and second language acquisition. Generally speaking, it is a difficult task to propose only one neat definition for transfer that includes all the different associated aspects. It is succinctly argued that transfer is concerned with the hypothesis that the learning of task A will affect the subsequent learning of task B. Now the substitution of task A and task B with L1 and L2 respectively will make it quite obvious that the psychological foundation of contrastive analysis (CA afterwards) is transfer theory (Ellis, 2008). The notion of transfer as a crucial theoretical construct of SLA theories was associated with contrastive analysis and likewise with behaviorism, hence, it temporarily lost ground with the behaviorist views of language acquisition. Since then, transfer has gone through a series of changes in its conceptualization and has been challenged by a number of researchers, such as Chomsky (1959).

In particular, when behaviorism, seemingly, failed to give neither a satisfactory account of the learner's first language influence nor that of the previously acquired ones, therefore transfer was found to be inappropriate to encompass the full range of language contact effects (e.g., avoidance, borrowing, language loss). As a result, the term transfer was limited to refer to the incorporation of elements from one language to another and the researchers in the field (e.g. Sharwood, Smith, and Kellerman), instead, came up with the theory neutral term Cross Linguistic Influence (CLI) which is used as an umbrella term to encompass the phenomena of transfer, interference, avoidance, borrowing etc. none of which are synonymous. As is evident, despite the fact that Odlin (1989), embracing the behaviorist views, has notably defined transfer as the influence resulted from similarities and differences between the target language and all the previously (and perhaps imperfectly) acquired languages, 
Since the year dot, the first language was considered to be the main source of transfer in the acquisition of all subsequent languages. As well as the different views about the definition of transfer, different terminologies have emerged to refer to this phenomenon such as language transfer, linguistic interference, the role of mother tongue, native language influence and language mixing (Odlin, 1989).

Casting our net widely, the study of bilingualism has corroborated many of the experimental findings concerning the effect of transfer. Studies by Jordens (1990), Kellerman (1977, 1978, 1983) and others were instrumental in leading the field of second language acquisition to a new perspective in the history of transfer research which is the shift of attention from transfer to transferability. This was a shift from the documentation of cases of transfer to more fundamental investigation of what makes material likely to be transferred in the first place. In Kellerman's terms, not everything that looks transferable is transferable. In fact, Kellerman and Smith (1986) developed the concept of transferability to refer to the probability with which a structure will be transferred relative to others. Anderson (1983) has developed the influential 'transfer to somewhere' principle to include the constraint that the L1 structure must be consistent with natural acquisitional principles, and preferred structures should be free, invariant, functionally simple, and frequently occurring morphemes. This perspective developed partly in reaction to $\mathrm{CAH}$. With the emerging field of L3 acquisition the role of prior language knowledge has become even more nuanced. Not only do researchers continue to ask whether and when transfer will take place in interlanguage development, but they additionally ponder on the specific interplay between the L1, L2, and L3, and the potential source of transfer from any previously known languages in the initial and subsequent development. Notwithstanding the wide range of perspectives on the notions of transfer and cross-linguistic influence, it is now common for both transfer and CLI to be used interchangeably to refer to the same phenomenon. In fact, despite the fact that transfer was for some time associated with the behaviorist theory of language learning, according to Jarvis and Pavlenko (2008), both terms can be considered as neutral umbrella terms.

\section{Variables condition syntactic transfer during multilingual acquisition}

The study of cross-linguistic influence in multilingual acquisition, presenting more diversity than second language acquisition, is complex because of the number of potential factors that are associated with it and their possible interaction. In fact, different variables are put together to determine the likelihood of transfer within the confines of a rule-governed system. Addressing the variables which affect the type and extent of CLI during multilingual development will notably divulge some of the complexities and unique features that characterize the process of additional language acquisition. With respect to the fact that a myriad of factors are involved and interact when languages come into contact, it is pertinent to mention Selinker and Lakshmanan (1993) Multiple Effects Principle (MEP) according to which when two or more factors work in tandem, there is a greater chance of stabilization of interlanguage forms leading to possible fossilization. In principle, there are two main groups of factors that have an impact on all transfer behavior; these factors can be loosely divided into sample free language-based and learner-specific variables (Falk, 2010). The role of the former, among other things, draws attention to the issue of language distance between the languages involved. Each of these variables is operative during contact between several languages or say, multilingual dynamic.

\subsection{Language-based variables}

Language typology - The evolution of the studies on CLI is in turn an evolution in the perspectives on the role of different variables in language transfer and so far, (psycho) typology or relative similarity, congruent structures and shared feature values between a multi-lingual's languages, seems to be amongst the most important variables in conditioning syntactic transfer during multilingual acquisition. Early empirical studies on language transfer among different learners of different L1 backgrounds have shown that language typology overrides other factors such as proficiency and amount of L2 exposure. A critical distinction must be made between historical and formal typology. Whereas the former refers to languages that are genetically related to each other, the latter looks at the structure of languages, independent of their generic ties. The correlation 
between language typology and transfer during third language acquisition suggests that typological closeness between L2 and L3 essentially facilitates language transfer (Cenoz, 2001; De Angelis \& Selinker, 2001; Ringbom, 2001).

Research focusing on the lexical level of language acquisition, with transfer of word forms being more prevalent between languages that are typologically similar in relation to those that are not, regardless of order of acquisition, offers language typology (Cenoz, 2003) or even psycho-typology (Kellerman, 1983; Ringbom, 2001) as one of the principal predictors of source of inter-language transfer in the L3 learner. The most revealing study of the role of typology in multilingual acquisition involves the comparison of L3 learners who have a close L1 and a distant L2, to L3 learners with a distant L1 and a close L2 (Cenoz \& Cenoz, 2001). In the comparison of Basque L1 and Spanish L1 children learning L3 English, the Basque L1 learners, a language typologically distant from English, show more evidence of lexical transfer from their L2 Spanish than the native Spanish speakers do. Foote (2009) in her generative approach to L3 acquisition has tried to determine if it is also the case for morpho-sytanx that language typology influences whether transfer will come from the L1 or the L2. Results suggest that transfer may come from either L1 or L2, depending on language typology or more precisely, whether the languages share the particular features in question.

Frequency and markedness - The frequency with which a particular linguistic feature appears in the L1 increases the likelihood of being transferred to L2 (Larsen-Freeman, 1997). As perceived by the learners, an infrequent item will be considered psychologically marked and thus less transferable (Kellerman, 1983). From a language processing perspective, highly frequent L1 lexical items are likely candidates for unintentional lexical transfer due to their high activation levels at the initial state of L2 acquisition. It gives the impression that at low L2 proficiency and with limited L2 exposure, highly frequent L1 items can be unintentionally incorporated in an L2 utterance even when the speaker is not in code-switching mode to fill a lexical fact (Murphy, 2005). From this, we come to an alternative concept which is considered as another area of linguistic enquiry -the study of markedness. According to (Ellis, 1994), the general idea behind the view is that some structures are more natural or basic than other structures. But the concept is in fact characterized by a host of linguistic views and very little consensus with respect to SLA. While in typological linguistics, those structures common to the world's languages are considered to be unmarked, In Chomskyan linguistics, universal grammar (UG) is a major determinant of un/markedness. Accordingly, unmarked structures are those governed by UG and thus require minimal evidence for acquisition. Then seemingly, marked structures fall outside UG. Additionally, attempts have also been made to distinguish degrees of markedness in the different settings of a parameter of UG. For instance, local binding of reflexives is considered unmarked in relation to long-distance binding. The general consensus is that the learner is more likely to transfer the more natural and unmarked features such as free morphemes from any of the potential sources of transfer into the target language.

Morphological transfer - Morphological inter-language transfer refers to the production of interlanguage forms in which a free or bound morpheme from previously known languages (non-target) is mixed with a different free or bound target morpheme to form a target language word. In the context of second or third language acquisition, the general consensus among researchers is that L1 morphemes are more likely to be transferred if they are free rather than bound (Fuller, 2009; Murphy, 2005). According to the model proposed by Myers-Scotten (1993) it is explicitly claimed that in a mixed utterance, system morphemes and particularly bound morphemes, must come from the matrix language. In the case of second or third language acquisition the target language function as the matrix language in which L1 or L2 items are embedded.

\subsection{Learner-based variables}

Proficiency level in the target and the source languages - Proficiency is a determining factor with respect to the likelihood of language transfer during multiple language acquisition. It is agreed amongst the researchers that language transfer is more likely to occur at lower levels of target language proficiency (e.g. Ringbom, 1987). As a result it could be contended that there is a negative correlation between target language proficiency and 
transfer as the lower the target language proficiency the more the likelihood of transfer from previous linguistic repertoire will be. According to Odlin (1989) the correlation between L2 proficiency and transfer applies primarily to negative transfer, whereas certain types of transfer occur even at high levels of proficiency. Similarly based on the proposed threshold hypothesis by Cummins (1979) it is maintained that bilinguals need to achieve a certain level of proficiency before any positive cognitive benefits become evident such that limited bilingualism results in negative cognitive effects. Given the complex linguistic configuration of the multilingual, the general consensus is that much L2 to L3 transfer is the result of low L2 proficiency. There is controversy, amongst the researchers, over the direction of language transfer in multilingualism. Whereas Hammarberg, Cenoz, Hufeisen, and Jessner (2001) accentuate the role of L2 competence in the likelihood of material transfer from L2 to L3, Shanon (1991) had pointed out that often the most recently acquired, and therefore the weakest language is the source of transfer. But it must be noted that Shanon's observation applies to the lexical borrowings that are not morpho-syntactically adapted to the target language. As a matter of fact, generalizing the claims about transfer from one language to another in one level say, phonology or lexicon to others i.e. morphology or syntax or even from one domain to others, should be regarded with great skepticism. But generally speaking, lexical transfer and language switches decrease as L3 proficiency increases, L2 influence diminishes twice as quickly as L1 influence (Hammarberg et al., 2001). Results of the study by Jaensch (2008) suggests that even in the case of certain L3 features that the learners have not encountered either in L1 or L2, those L3 learners who have achieved a higher proficiency in L2 are more target-like in their performance than those learners of an equivalent L3 proficiency but a lower L2 proficiency.

Linguistic awareness - The multilingual learner's linguistic awareness is a key variable in his language performance and acquisition process and is directly related to educational background (Murphy, 2005). The higher level of metalinguistic awareness facilitates the acquisition of language by exploiting the cognitive mechanisms underlying the processes of transfer and enhancement (Jessner, 1999). In fact, awareness is not limited to linguistic structures and semantics but also affects phonological, pragmatic, sociolinguistic knowledge, and cross-linguistic influence can occur in any of these domains. This will have implication for the learner's ability to notice native-and target-language linguistic features. Though a discussion of the varying roles of conscious and unconscious awareness is beyond the scope of this section, it is pertinent to mention that according to Kellerman (1983); Kellerman and Smith (1986) multiple levels of awareness are operative during transfer.

According to previous findings, two claims are made: CLI decreases with increase in L3 exposure (Dewaele \& Regan, 2001), and the higher the amount of L2 exposure, the higher the L2 influence is on the L3 (cited in Ringbom, 1987; Tremblay, 2006). Cook's notion of multilingual competence or the compound state of a mind with multiple grammars refers to a multilingual linguistic competence characterized by increased meta-linguistic awareness, greater creativity, and cognitive flexibility and more diversified mental abilities. Mägiste (1984) holds an active/passive distinction according to which the frequency of use leads to activation of knowledge and subsequently greater likelihood of transfer, while the passive knowledge of another language i.e. meta-linguistic awareness of another language supports Cook's notion of multi-competence. It is also noteworthy that amount of exposure could be regarded as going hand in hand with proficiency level in either of the languages at the disposal of the multilingual learner in a way that an increased amount of exposure would translate into an increased in proficiency level (Murphy, 2005).

Psychotypology - Psychotypology has been argued to be another primary factor in cross-linguistic influence. It could be succinctly defined as the learner's perception of language typology, whereby the learner's recognition of congruent forms between the native and target languages either facilitates or impedes with additive language acquisition (Kellerman, 1983). In other words, Kellerman's leading constraint on language transfer is the learner's own perception of language distance between the languages involved is a kind of Psychological constraint. He based his ideas on his work with L1 Dutch learners of L2 German and L2 English which divulged that L2 learners transferred L1 structures that they perceived transferable (Kellerman, 1992). The development of a psychotypology is inevitably fostered by the possession and the development of metacognitive skills under 
which metalinguistic awareness is subsumed. Within this perspective, he claims three principal interacting factors that control the use of transfer or cross-linguistic influence by learners: (1) learners' psychological structure of the native language; (2) learners' perception of the distance between their L1 and the TL; (3) learners' knowledge of the TL.

In a similar vein, the footprints of Kellerman's psychotypology can be discerned in the realm of L3 acquisition. According to this model, the learner's cognitive efforts, in the form of judgments, strategies and decisions, play a large if not decisive role in multilingual acquisition, that is, the language perceived by the learner to be more foreign-like or close to the target language could serve as the potential source of transfer even in the cases where that language may not be the most economical source of transfer. To be clear, in the case of third language acquisition, it is possible that one of the previously acquired systems provides the features and structures needed for (immediate) L3 convergence yet being perceived as the less typologically similar system to the target it is not activated for transfer, but the less economical language is activated based on perceived typological proximity.

Recency (Recency of use) -The recency effect is another factor that can potentially affect cross-linguistic influence. With respect to this variable, it is hypothesized that learners are more likely to borrow from a language they actively use than from other languages in their linguistic repertoire (Hammarberg \& Cenoz, 2001). An explanation behind this claim lies on the idea that the language that has been recently used is more accessible. Hammarberg (2001) has confirmed the influence of recency. He has provided evidence that learners use the most recently used language as a base language, this use could also be due to the subjects' higher proficiency or psychotypology, though. Shanon (1991), on the other hand, has reported the presence of a last language effect in the production of her participants. They were reported to be relying on the last language they had been in contact with, regardless of their level of proficiency. Dewaele (1999) has also offered additional evidence with regard to the order of acquisition and how the mind may establish a special kind of association between the language being acquired and the immediate previously learnt language.

Recency of acquisition - Some scholars believe that accessibility of the recent language happens not only for recency of use but also for recency of acquisition. In fact, with regards to order of acquisition, it could be argued that the mind may establish a special kind of association between the language being acquired and the immediate previously learnt language. Shanon (1991) and Dewaele (1999) have provided evidence in support of a 'last language effect' based on which learners seem to be relying on the last language they have learnt or been in contact with. But one may also notice that in Dewaele (1999) study, while the order of acquisition have seemingly overridden a potential typological effect, Dewaele's results do not rule out the possibility that proficiency influenced the language chosen as source of cross linguistic influence (CLI).

With respect to recency of acquisition or the so-called foreign language effect, it could be further argued that it occurs when an L3 learner chooses (whether consciously or unconsciously) to activate the first foreign language instead of the first language, where there might be more typological similarities. It is almost as if the student's mind concludes that his/her native language cannot possibly be foreign enough to compare to the target language, so the comparison between L2 and L3 must be made instead of comparing L1 to L3. There seems to be a desire to "suppress L1 in the belief that this is inherently 'non-foreign' and thus that using a non-L1 and hence 'foreign' language would be a better strategy in acquiring another 'foreign' language" (Williams \& Hammarberg, 1998). Stated slightly differently by Wood (2011), if a child grows up in a household that only speaks Spanish from birth until school-age at which time s/he begins learning English, the recency of English acquisition may influence the way the child learns a third language.

Language mode - The concept of language mode has driven many recent studies of cross-linguistic influence. Grosjean (2001) has defined language mode as the state of activation of bilingual/multi-lingual's languages and language processing mechanism at a given point in time. With respect to the continuous variable of language mode, there are two main notions of base and guest languages. Whereby the base language that 
The evolution of perspectives on the role of transfer during multilingual development

frames the utterances is totally active to govern language processing and the guest languages range from low to nearly total activation based on the learners proficiency level and linguistic awareness (Murphy, 2005). The application of this model to L3 acquisition is that while a bilingual in monolingual mode does not mix languages overt evidence of cross linguistic influence, a trilingual with low L3 proficiency in monolingual mode will not show signs of L1 influence in L3 productions but might still show signs of, often unconscious, L2 interferences (De Angelis \& Selinker, 2001; Ringbom, 2001).

Context - Even though seemingly bilingualism tends to exert a positive impact on additional language acquisition, the language acquisition contexts may be of outmost importance. The result of diverse methodological approaches used in different sociolinguistic environments offer insights that additive and subtractive environments are to a large extent determined by the development of the first language and its status. It could be further contended that apart from the environment, other individual and contextual factors can as well wield a strong influence on third language acquisition than bilingualism alone.

According to Ellis (1997), a multilingual learner's productions would be affected by three major types of contexts, namely, linguistic context, situational context, and psycholinguistic context. By linguistic context he means the feature to be used itself such as a verb in past tense and also the other constituents of the utterance which may alter the learner's choice of the past tense marker. For example the learner may supply different types of past tense marker (different from the target one) depending on whether or not the utterance contains an adverb of frequency. Learners also vary the linguistic forms they use in accordance with the situational context which is directly related to the situation in which they are producing their utterance and in this way they behave like the target language native speakers. As such, when they are talking to someone they do not know very well they tend to use more formal language. In this way, they are more likely to use the correct target-language forms in formal context and non-target forms in informal contexts. Another important factor that accounts for the systematic variability of the learner's language is the psycholinguistic context-whether learners have the opportunity to plan their production. A comparison of the learner's planned versus unplanned productions have revealed a variability in their choice of linguistic features in a way that the learners tend to produce more target-like forms when asked to produce planned utterances.

Age - With respect to age and language transfer, the general guideline is that child learners are less likely to draw on their L1 while learning L2, than are adult learners, but 'the younger is better' principle, while generally true, must be approached carefully, taking into account other possible variables(Murphy, 2005). In their respective reviews of age, Krashen, Long, and Scarcella (1979), Cook (1995), and Singleton (1989) come to general, if tentative, solutions that in naturalistic situations those whose exposure to a second language begins in childhood in general eventually surpass those whose exposure begins in adulthood, even though the latter usually show some initial advantage over the former. But, following this, it might be argued that research findings from naturalistic learning contexts have been somehow hastily generalized to formal learning contexts and the results of classroom research have been interpreted in the light of the assumptions and priorities of the former. Even though there is a large number of research studies on the controversial age factor in second language acquisition, as discussed above, research on the relationship between age and cross-linguistic influence in third language acquisition has less considered or say, received limited attention (Cenoz, 2000). In the case of young learners, age is associated with metalinguistic awareness and older children have been reported to advance more quickly in the initial state of second language acquisition. With respect to cross-linguistic influence, psycho-typologically, older learners have a more accurate perception of linguistic distance that could influence the source language they use when transferring terms from one of the languages they know.

In order to examine whether cross-linguistic influence is affected by age, Cenoz (2003) has compared the number of terms transferred by the three age groups from Basque and Spanish into English. The results indicate that older learners present more lexical cross-linguistic influence than younger learners. Cenoz attributes this difference to higher metalinguistic awareness which extends to typological judgment amongst the older subjects that makes transfer possible. While, the younger learners are less able to make judgments about typology and 
congruence of structures, the older learners avoid the typologically distant language as a source of transfer. Despite the fact that these results shed light on age-related effects in cross-linguistic influence, further studies comparing child learners to adults are needed to give a clearer indication of age-related differences in multilingualism.

\section{5. $\mathbf{L 3}$ acquisition hypotheses}

Having a closer look at the evolution of theories and hypotheses of the cross linguistic influence during third language acquisition will reveal the fact that not all researchers have accepted the importance of the role of transfer in additive language acquisition. Thus, the concept of transfer or say, cross linguistic influence, to use a more appropriate term to encompass the full range of language contact effects, is so far approached from different, often opposing and seemingly incompatible perspectives. Likewise, conducting a study on multiple language acquisition presupposes taking stock of the proposed hypotheses and differing ways of approaching data.

\subsection{Full Transfer/Full Access (FT/FA)}

In this proposal on third language acquisition, it is posited that all instantiations of the first language make up the initial theory about the second language and universal grammar (UG) fully constrains subsequent second (third) language development. White $(1985 \mathrm{~b}, 1989)$ was one of the first L2A theorists who adopted an approach that was later refined and called Full Transfer/Full Access by Schwartz and Sprouse (1994); Schwartz and Sprouse (1996). On the basis of experimental studies investigating the pro-drop parameter, White $(1985,1986)$ concluded that L2 learners start out with the L1 parameter value and then reset it to the target language value. Schwartz and Sprouse (1994) illustrate their proposal by means of the longitudinal case study of a Turkish learner of German. Their focus is on the learner's verb placement, and particularly on the temporary asymmetry between pronominal and non-pronominal subjects he exhibits in inversion constructions. Simply put, FT/FA hypothesizes that the initial state of L2 acquisition is the final state of L1 acquisition (Full Transfer) and that failure to assign a representation to input data will force subsequent restructurings, drawing from options of UG (Full Access) (Schwartz \& Sprouse, 1996).

\subsection{L2 Status Factor Hypothesis (LSFH)}

The phenomenon of L2 activation in L3 was labeled 'the L2 status factor' by Williams and Hammarberg (1998), referring to the learner's inclination to activate a previously acquired second language when producing in an L3 (Bardel \& Falk, 2007). Hammarberg et al. (2001) suggest that L2 status is an important factor in L3 acquisition. He maintains that amongst the languages which are at the learners' disposal i.e. L1 and L2, the L2 is more likely to have an impact on the process of L3 acquisition. In the last two decades, studies have emerged which indicate the qualitative difference between the acquisition of a true L2 and the subsequent non-native languages (L3) (Bardel \& Falk, 2007; Flynn et al., 2004; Hammarberg et al., 2001; Hufeisen, 2000). It has been proposed that 'L2 status' defined by Hammarberg as 'a desire to suppress L1 as being non-foreign and to rely rather on an orientation towards a prior L2 as a strategy to approach the L3' (Hammarberg et al., 2001, pp. 36-37).

In a similar vein, De Angelis $(2005,2007)$ accounts for a higher degree of activation of an L2 than the L1 using the two psycholinguistic constraints of perception of correctness and association of foreignness. In principle, the L2 status factor is a natural outcome of sociolinguistic and cognitive differences between L1 and L2 acquisition, such as age of onset, proficiency level, learning situation, metalinguistic awareness, learning strategies present only in L2 and awareness of the language learning process in L2 which is, tout court, absent in L1. 


\subsection{Cumulative Enhancement Model (CEM)}

An influential model that has driven much of the research on the cross linguistic influence in L3 acquisition is Flynn's cumulative enhancement model (a model that make use of the Vinnitskaya et al. 2002 study). As one of the first generative attempts at modeling morpho-syntactic multilingual transfer, Flynn et al. (2004) argued that despite the essentially universal multilingualism in the world, our understanding of language acquisition is very restricted and that the investigation of L3 acquisition provides essential new insights about the language learning process that would not possible in the context of an L1 or L2 study alone. The so-called CEM for multilingual transfer claims that all previously learnt knowledge in the learner's linguistic repertoire be it L1, $\mathrm{L} 2, \ldots . \mathrm{L}_{\mathrm{N}}$, can potentially modify the course of L3 syntactic development in a positive way. Simply put, the CEM assumes positive transfer or no transfer at all (Rothman \& Amaro, 2010). This effectively sidesteps the possibility of negative transfer of previous linguistic knowledge and it is a hypothesis to be tested empirically, which the present study takes up.

\subsection{Typological Primacy Model (TPM)}

Built upon the suggestions of (psycho)typological factors by Rothman and Amaro (2010) and later modified by Rothman (2011) under the label Typological Primacy Model (TPM), this approach to determine what variables condition syntactic transfer during multilingual acquisition, forcefully posits that initial state of transfer for multilingualism occurs selectively based on the comparative typological distance or perceived typology i.e. (psycho)typological proximity of the language pairings involved. Syntactic properties of the closest (psycho)typological language, either of the previously known languages be it L1 or L2, constitute the initial state hypothesis in multilingualism even if it is not the most economical option or simply put, it impedes rather than trigger the third language development. To be clear, like CEM, the TPM reconciles the juxtaposing observations that the L1 and L2 apparently both provide a viable source of transfer in L3; however, TPM crucially differ from CEM in that only the former anticipate the possibility of non-facilitative transfer by stipulating that comparative (psycho) typology plays, when relevant given the grouping of languages, the most deterministic role in transfer selection.

\section{An anthology of generative studies on syntactic transfer in L3 acquisition}

Generally speaking, multilingualism with particular reference to the CLI, is the study of how additive languages are learned, in other words, it is the investigation of the acquisition of a non-primary language. The prediction and interpretation of the interaction amongst several languages in additive language learning or simply put, the role of transfer in third language acquisition, has been well a topic of interest for scholars and researchers in the field. Since the emergence of the field the body of knowledge has seen increased sophistication.

\subsection{Flynn et al. (2004)}

Flynn et al. (2004) in their pioneering generative study on third language acquisition by adults and children have accentuated the need for a genesis to investigate the acquisition of a third language in order to unconfound certain factors left confounded in first and second language acquisition. Examining the production of restrictive relative clauses by three groups of learners: Japanese, Spanish and Kazakh native speakers; the latter having L2 Russian it was empirically demonstrated that the L1 is not the only source for L3 transfer at the level of formal syntactic features and functional categories. Propagating the Cumulative Enhancement Model (CEM), they proposed that language acquisition has a scaffolding effect in the sense that any previously learned language will either enhance subsequent language acquisition or crucially remain neutral. It is simply put, assumed that each language learned and represented in the mind of the learner is could be equally drawn upon in subsequent language acquisition. Flynn (2009) has also addressed the question of access to UG in L2, L3 and $\mathrm{L}_{\mathrm{n}}$ acquisition and has claimed that UG is constantly accessible, independently of how many specific language grammars are 
Tavakol, M., \& Jabbari, A. A.

being created in the mind of the multilingual learner.

Table 1

A synopsis of the study by Flynn et al. (2004)

\begin{tabular}{|c|c|c|c|c|}
\hline \multirow{2}{*}{ Target language } & \multicolumn{2}{|c|}{ Linguistic repertoire } & \multirow{2}{*}{ Group } & \multirow{2}{*}{ Pattern of acquisition } \\
\hline & $\mathrm{L} 1$ & $\mathrm{~L} 2$ & & \\
\hline English as L1 & $\begin{array}{l}------ \\
\end{array}$ & $\begin{array}{l}------ \\
\end{array}$ & Children & $\begin{array}{l}\text { Free relative precedes lexically headed } \\
\text { relative clause }\end{array}$ \\
\hline English as L2 & Japanese & ------- & Adults & $\begin{array}{l}\text { Free relative precedes lexically headed } \\
\text { relative clause }\end{array}$ \\
\hline English as L2 & Spanish & ------- & Adults & $\begin{array}{l}\text { Free relative does not precede } \\
\text { lexically headed relative clause }\end{array}$ \\
\hline English as L3 & Kazakh & Russian & Adults & $\begin{array}{l}\text { Free relative does not precede } \\
\text { lexically headed relative clause }\end{array}$ \\
\hline
\end{tabular}

Leung (2009) has also addressed the question of access to UG in L2, L3 and Ln acquisition and has claimed that UG is constantly accessible, independently of how many specific language grammars are being created in the mind of the multilingual learner.

\subsection{Bardel and Falk (2007)}

In an attempt to provide counter-evidence to DMTH and PT (Håkansson et al., 2002) and in favor of syntactic transfer from L2 to L3, by comparing learners with different L1s and L2s in terms of the placement of negation in the initial state of L3 Swedish and Dutch, Bardel and Falk (2007) not only indicated the qualitative difference between the acquisition of a true second language and the subsequent acquisition of a third language but they also claimed that the L2 exerts such a strong effect on the L3 that it may even block the positive transfer of the L1 on the acquisition of certain syntactic features that are present in the L1 and /13 but not the L2. In the 2007 study which was based on the ideas originally put forward in Bardel and Falk (2004) and Sjögren (2002), the role of the L2 in syntactic transfer was discussed through the comparison of two groups' L3 acquisition of the placement of sentential negation in either L3 Swedish or Dutch at the absolute initial state. One group had an L1 with V2 and an L2 without V2, and other groups had an L1 without V2 and an L2 with V2. The results demonstrated that the L2 status factor enables L2 syntactic structures to be transferred into an L3, independently of typology and may block L1 transfer from appearing even though it would yield target-like structures. Ina later study by Falk and Bardel (2010), the L2 status factor is further tested on two groups of intermediate learners of German as an L3. One group has L1 English and L2 French and the other group has L1 French and L2 English. Here they test the participants on the placement of object pronouns in German main and subordinate clauses. The results corroborates the presence of the L2 status factor hypothesis noted in the 2007 paper, even at an intermediate proficiency level of the L3.

\subsection{Rothman and Amaro (2010)}

Three outstanding L3 acquisition hypotheses i.e. the CEM, the L2 status factor and FT/FA discussed above are further tested and supported by Rothman and Amaro (2010). They have compared the acquisition of French and Italian as either L2 or L3 learners with a special interest in the Null-Subject Parameter in the two groups. While Spanish and Italian are pro-drop languages, English and French are not. The data has revealed that properties of NSP are not transferred from L1 English but from L2 Spanish into L3 French or Italian. The results of their study clearly dismiss the FT/FA at the initial state of L3 acquisition while corroborate the L2 status factor discussed above. With respect to CEM as proposed by Flynn et al. (2004) which suggested that both L1 and/or L2 can be transferred equally in a positive sense yielding correct structures if the parameter/feature is present in either of the background languages, the study do not falsify it, instead they suggest a modified version where (psycho) typology may be a factor influencing the source of transfer. 
Building upon the data from Rothman and Cabrelli Amaro (2007, 2010) and Bardel and Falk (2007), Rothman (2011) further provided evidence in support of the position that the CEM is not entirely correct insofar as multilingual transfer is not always facilitative based on either an L2 effect or typological determinacy. Rothman tested two groups of learners of Brazilian Portuguese as an L3, one with L1 English/ L2 Spanish and a second group with L1 Spanish / L2 English on the acquisition of noun-raising, a phenomenon that is present and obligatory in all languages of the study, Except for English. All learners successfully control the noun-raising rule, a fact that Rothman explains in terms of transfer from either L1 or L2. This seminal study on L3 syntactic transfer selectivity, therefore argues in favor of Typological Primacy Model (TPM) as a modification of the CEM which differently predicts that transfer obtained from either the L1 or L2 is not neutralized simply when it is not facilitative based on either perceived or actual typological proximity. This model could explain the findings of Leung (2009), who also conducted studies on two typologically proximate languages and one that is not proximate.

To sum up, in recent years an impressive number of formal syntactic studies have been conducted and mainly suggested four influential models:

D $\quad$ 1 maintains a privilege role on the acquisition of subsequent languages

All background languages have a positive role effect on the acquisition of subsequent languages

> L2 may hinder L1 transfer in both a positive and negative manner, as predicted by the L2 status factor

$>$ Typological factors determine transfer from L1 or L2

Despite the fact that such studies comprise an infinitesimal part of all generative studies investigating adult non-primary acquisition, much of the work that has been done to this point have significant implications for future research.

\section{Conclusion}

To conclude, an overview of the studies conducted on L3 acquisition indicates a common ground shared across all of them in taking the position that L3 acquisition is not simply another case of L2 acquisition and that the emergence of the principles and parameters framework has had a great contribution to the field of multilingualism. However, proposals regarding the role of previously acquired languages in the acquisition of a target language (L3) divulge that the data are approached from various, often opposing and seemingly incompatible viewpoints. At time, it could be contended that TPM as a modified version of CEM could be adopted as the model which, de facto, rightfully account for the true nature of L3 acquisition excluding notions such as reverse transfer; but, the major drawback of this model as the previous ones is that it has not been tested to investigated the situation of polyglot. In other words, the scenario is not extended beyond $\mathrm{L} 3$ to include $\mathrm{L} 4 / \mathrm{L}_{\mathrm{N}}$ and it is not clear how the researchers should determine the real concept of the term psychotypology in terms of structural, historical and perceived closeness when examining the interaction amongst more than three languages. Apart from the fact that the study has direct implications for applied linguists and the researchers in the field as to obtain a holistic view of the true architecture of L3 acquisition/multilingualism, how it has been challenged so far, and how it should be further investigated by extending the context to include more languages at various language levels, it should be further noted that the end results of the study have pedagogical implications as far as learners and practitioners concern. To be clear, a common trend in language teaching has been to keep previously learned languages out of the classroom with this strict separation aiming to prevent the potential of the known languages interference on the one being learnt.

Research on multilingualism, including this review study which gives an overview of such research studies, could divulge if multi-linguals keep their languages apart or on the contrary there are links and interaction 
Tavakol, M., \& Jabbari, A. A.

between the different languages in the mind of the learners. These findings have explicit effects on the changing of the classroom policies taken by teachers in a way that they can help their students profit from their prior language knowledge by incorporating explicit references to similarities between languages, since learners may not always be able to concentrate on theses similarities on their owns. Therefore, it can help the language teachers to be cautious of the differences that might exist in bilinguals and multilinguals in acquiring a new language and facilitate the task of teaching as well.

\section{References}

Bardel, C., \& Falk, Y. (2004). Can processability be transferred. Paper presented at the Fourth International Symposium on Processability, Second Language Acquisition and Bilingualism. University of Sassari.

Bardel, C., \& Falk, Y. (2007). The role of the second language in third language acquisition: The case of Germanic syntax. Second Language Research, 23(4), 459-484. http://dx.doi.org/10.1177/0267658307080557

Cenoz, J. (2000). Research on multilingual acquisition. English in Europe: The acquisition of a third language, 14(6), 39-53.

Cenoz, J. (2003). The role of typology in the organization of the multilingual lexicon. The multilingual lexicon, 23(4), 103-116. http://dx.doi.org/10.1007/978-0-306-48367-7_8

Cenoz, J. (2005). English in bilingual programs in the Basque Country. International journal of the sociology of language, 205(171), 41-56.

Cenoz, J., \& Cenoz, J. (2001). The effect of linguistic distance, L2 status and age on cross-linguistic influence in third language acquisition. Cross-linguistic influence in third language acquisition: Psycholinguistic perspectives, 111(45), 8-20.

Cook, V. (1985). Chomsky's universal grammar and second language learning. Applied Linguistics, 6(1), 2-18. http://dx.doi.org/10.1093/applin/6.1.2

Cook, V. (1995). Multi-competence and effects of age. In D. Singleton and Z. Lengyel (Eds.), The age factor in second language acquisition: A critical look at the critical period hypothesis (pp. 51-56), Clevedon: Mutilingual Matters.

Cummins, J. (1979). Linguistic interdependence and the educational development of bilingual children. Review of educational research, 49(2), 222-251. http://dx.doi.org/10.3102/00346543049002222

De Angelis, G. (2005). Interlanguage transfer of function words. Language learning, 55(3), 379-414. http://dx.doi.org/10.1111/j.0023-8333.2005.00310.x

De Angelis, G. (2007). Third or additional language acquisition (Vol. 24). Multilingual Matters Limited.

De Angelis, G., \& Selinker, L. (2001). Interlanguage transfer and competing linguistic systems in the multilingual mind. Bilingual Education and Bilingualism, 60(4), 42-58.

Dewaele, J. M. (1999). Word order variation in interrogative structures of native and non-native French. International Journal of Applied Linguistics, 30(123), 161-180.

Dewaele, J. M., \& Regan, V. (2001). The use of colloquial words in advanced French interlanguage. Eurosla Yearbook, 1(1), 51-67. http://dx.doi.org/10.1075/eurosla.1.07dew

Ellis, R. (1994). The study of second language acquisition: Oxford University Press, USA.

Falk, Y. (2010). Gingerly studied transfer phenomena in L3 Germanic syntax: The role of the second language in third language acquisition.

Flynn, S., Foley, C., \& Vinnitskaya, I. (2004). The cumulative-enhancement model for language acquisition: Comparing adults' and children's patterns of development in first, second and third language Acquisition of relative clauses. International Journal of Multilingualism, 1(1), 3-16. http://dx.doi.org/10.1080/14790710408668175

Foote, R. (2009). Transfer in L3 acquisition: The role of typology. Third language acquisition and universal grammar, 45(8), 89-114.

Fuller, J. M. (2009). Multilingualism in Educational Contexts: Ideologies and Identities. Language and Linguistics Compass, 3(1), 338-358. http://dx.doi.org/10.1111/j.1749-818X.2008.00101.x 
The evolution of perspectives on the role of transfer during multilingual development

Grosjean, F. (2001). The bilingual's language modes. One mind, two languages: Bilingual language processing, 7(11), 1-22.

Hammarberg, B., Cenoz, J., Hufeisen, B., \& Jessner, U. (2001). Roles of L1 and L2 in L3 production and acquisition. Cross-linguistic influence in third language acquisition: Psycholinguistic perspectives, $70(8), 21-41$.

Herdina, P., \& Jessner, U. (2000). The dynamics of third language acquisition. English in Europe: The acquisition of a third language, 18(1), 84-98.

Hufeisen, B. (2000). A European Perspective: Tertiary Languages With a Focus on German as L3. Handbook of undergraduate second language education, 12(7), 209-213.

Jaensch, C. (2008). L3 acquisition of articles in German by native Japanese speakers. Paper presented at the Proceedings of the 9th Generative Approaches to Second Language Acquisition Conference (GASLA 2007). Somerville, MA: Cascadilla Proceedings Project.

James, C. (1980). Contrastive analysis: Longman Pub Group.

Jessner, U. (1999). Metalinguistic awareness in multilinguals: Cognitive aspects of third language learning. Language Awareness, 8(3), 201-209. http://dx.doi.org/10.1080/09658419908667129

Jessner, U., \& Onysko, A. (2006). Linguistic awareness in multilinguals: English as a third language. The South Florida Journal of Linguistics, 7(14), 151-162.

Jordens, P. (1990). The acquisition of verb placement in Dutch and German. Linguistics, 28(6), 1407-1448. http://dx.doi.org/10.1515/ling.1990.28.6.1407

Kellerman, E. (1983). Now you see it, now you don't. Language transfer in language learning, 54(12), 112-134.

Kellerman, E., \& Smith, M. S. (1986). Crosslinguistic influence in second language acquisition: Pergamon Institute of English.

Krashen, S. (1981). Second language acquisition. Second Language Learning.

Krashen, S., Long, M. A., \& Scarcella, R. C. (1979). Age, rate and eventual attainment in second language acquisition. Tesol Quarterly, 573-582. http://dx.doi.org/10.2307/3586451

Larsen-Freeman, D. (1997). Chaos/complexity science and second language acquisition. Applied linguistics, 18(2), 141-165. http://dx.doi.org/10.1093/applin/18.2.141

Leung, Y. k. I. (2006). Full transfer vs. partial transfer in L2 and L3 acquisition. Inquires in Linguistic Development. In Honor of Lydia White, 7(12), 157-188.

Leung, Y. k. I. (2009). Third language acquisition and universal grammar (Vol. 37): Multilingual Matters Limited.

Mägiste, E. (1984). Learning a third language. Journal of Multilingual \& Multicultural Development, 5(5), 415-421. http://dx.doi.org/10.1080/01434632.1984.9994170

Murphy, S. (2005). Second language transfer during third language acquisition. Teachers College, Columbia University Working Papers in TESOL \& Applied Linguistics, 3(1), 1-18.

Odlin, T. (1989). Language transfer: Cross-linguistic influence in language learning: Cambridge University Press. http://dx.doi.org/10.1017/CBO9781139524537

Ringbom, H. (2001). Lexical transfer in L3 production. Bilingual Education and Bilingualism, 19(24), 59-68.

Rothman, J., \& Amaro, J. C. (2010). What variables condition syntactic transfer? A look at the L3 initial state. Second Language Research, 26(2), 189-218. http://dx.doi.org/10.1177/0267658309349410

Schwartz, B. D., \& Sprouse, R. (1994). Word order and nominative case in nonnative language acquisition: a longitudinal study of (L1 Turkish) German interlanguage. Language acquisition studies in generative grammar, 31(4), 71-89. http://dx.doi.org/10.1177/026765839601200103

Schwartz, B. D., \& Sprouse, R. A. (1996). L2 cognitive states and the Full Transfer/Full Access model. Second Language Research, 12(1), 40-72.

Selinker, L. (1996). On the notion of 'IL competence'in early SLA research: an aid to understanding some baffling current issues. Performance and competence in second language acquisition, 8(14), 92-113.

Singleton, D. (1989). Language Acquisition: The Age Factor. Multilingual Matters 47: ERIC.

Williams, S., \& Hammarberg, B. (1998). Language switches in L3 production: Implications for a polyglot speaking model. Applied linguistics, 19(3), 295-333. http://dx.doi.org/10.1093/applin/19.3.295 
Tavakol, M., \& Jabbari, A. A.

Wood, T. J. (2011). Third Language Acquisition: Spanish-Speaking Students in the Latin Classroom. Aliquid Novi, 17(8), 14-28. 